\title{
UMA GEOGRAFIA DA COOPERAÇÃO UNIVERSITÁRIA FRANÇA- BRASIL, ANÁLISE DOS ACORDOS ACADÊMICOS CAPES-COFECUB
}

Hérvé Théry Directeur de recherche au CNRS-Credal. Professor convidado na USP

hthery@aol.com

Resumo

Palavras-chave:

\section{Résumé}

Mots-clef :

\section{$0 \bigcirc 0$}

\section{INTRODUÇÃO}

Um artigo publicado no dia 25 de maio de 2009 no site do Ano da França no Brasil, abria-se, sob o título "Seminário comemora 30 anos de cooperação franco-brasileira com resultados positivos", com as seguintes informações.

Em trinta anos, o acordo de cooperação universitária entre o Brasil e a França, o "Capes/Cofecub", atendeu 659 projetos em todos os campos disciplinares ${ }^{1}$ e cerca de 1.600 estudantes brasileiros desenvolvem atualmente projetos na França, por meio do programa. [...] O presidente do Cofecub, Pierre Jaisson, atribui o sucesso das três décadas de acordo às afinidades que existem entre a França e o Brasil, principalmente na seara das iniciativas científicas. "Entre os dois países existe um sentimento de identidade e complementaridade. É um antigo caso de amor entre a França e o Brasil, e uma afinidade de mentalidades latinas. O Brasil está [“...] à altura da França, com seu dinamismo, seu desenvolvimento extremamente rápido e suas potencialidades de pesquisa", colocou.

"O Capes/Cofecub é a base, o solo para outros projetos de cooperação, e que permite renovar o cenário de pesquisa em ambos os países", afirmou Pierre Colombier, conselheiro de Cooperação e Ação Cultural da Embaixada da França no Brasil. "É a matriz, que faz com que apareça uma nova geração de pesquisadores", acrescentou. [...]

Já o presidente da Capes, Jorge Guimarães, classifica o começo do programa como "modesto e assimétrico", com a ida de mais brasileiros para a França do que o caminho inverso. E chamou o que acontece hoje como "momento mais simétrico", festejando o equilíbrio que há entre o intercâmbio de pesquisadores nos dois países. E pontua que o número de bolsistas brasileiros que optam por estudar na França, através 
do programa de cooperação, supera os que tiveram como destino os Estados Unidos. "No ano passado, 1.192 estudantes brasileiros receberam bolsas de estudo para ir à França, ante 946 para os EUA".

Considerado a "base, o solo para outros projetos de cooperação", que "permite renovar o cenário de pesquisa em ambos os países", o acordo de cooperação universitária Capes-Cofecub merece, portanto, nesta mesa-redonda "75 anos da cooperação geográfica universitária França - Brasil”, um estudo específico, duplamente geográfico. Geográfico por prestar uma especial atenção à localização dos projetos na França e no Brasil, aos intercâmbios que eles configuram entre cidades dos dois países, e por se focar no final nos projetos concluídos entre departamentos de geografia. Os dados disponíveis nos sites da Capes e do Cofecub foram usados para um estudo estatístico e cartográfico que recapitula e visualiza os 750 projetos aprovados e executados nestes trinta anos.

\section{PRINCÍPIOS E MODALIDADES DO ACORDO CAPES-COFECUB}

O programa Capes/Cofecub (fundado no acordo de cooperação científica inter-universitária assinado entre o Brasil e a França no dia 5 de outubro de 1978), caracteriza-se pelo apoio binacional a projetos de pesquisa e a formação de recursos humanos de alto nível, vinculados a Programas de Pós-Graduação de Instituições de Ensino Superior (IES) e de Pesquisa. O Programa tem por objetivos incentivar o intercâmbio científico e estimular a formação e o aperfeiçoamento de pós-graduandos e docentes.

As entidades responsáveis pelo programa são, pelo Brasil, a Coordenação de Aperfeiçoamento de Pessoal de Nível Superior - Capes e pela França, o Cofecub, o Ministère des Affaires Étrangères (Relações Exteriores) e o Ministère de l'Éducation Nationale (Educação).

Cada equipe é, preferencialmente, composta por até quatro pesquisadores vinculados a curso de doutorado de uma ou mais universidade(s) brasileiras e tem como coordenador um docente com título de doutor há pelo menos quatro anos, ela pode apresentar apenas uma proposta de projeto, que deve atender obrigatoriamente, aos seguintes requisitos:

. apresentação simultânea, pelas duas equipes, francesa e brasileira, ao Cofecub e a Capes respectivamente, com a justificativa da pertinência da parceria;

. duração prevista de quatro anos, salvo parecer contrário dos comitês científicos das entidades responsáveis pelo Programa, emitido durante a avaliação parcial, realizada no $2^{\circ}$ ano de execução do projeto (neste caso, a duração do projeto é de apenas 2 anos);

. promoção do aperfeiçoamento da formação de doutores e docentes, por intermédio de estágio acadêmico, "doutorado sanduíche" e estágio pós-doutoral;

As modalidades de apoio são a concessão de missões de trabalho, bolsas de estudo e recursos de custeio para o projeto, mediante envio de planejamento prévio pelo coordenador. Missões de trabalho consistem em viagem de membro da equipe do projeto, com duração entre 10 e 21 dias, o número de missões de trabalho concedidas anualmente para cada projeto sendo definido em conjunto pela Capes e pelo Cofecub e informado aos coordenadores. Bolsas de Estudo (duas por ano) são concedidas para a execução do projeto. Os estudantes brasileiros são indicados pelo coordenador do projeto, e as bolsas podem ser de pós-doutorado ou estágio de doutorando no exterior.

A apresentação da proposta de projeto de pesquisa é feita via internet, e deve ser apresentada simul- 
taneamente pela equipe francesa ao Cofecub e pela equipe brasileira à Capes. Consultores especialistas indicados pela Capes e pelo Cofecub analisam o mérito científico da proposta, considerando a coerência do projeto e relevância do tema proposto e a adequação do perfil acadêmico dos membros da equipe ao tema do projeto. Os comitês científicos da Capes e do Cofecub, elaboram independentemente a priorização das propostas viáveis recebidas, que é depois comparada, com vistas a uma decisão final comum.

\section{PARTICIPANTES, EVOLUÇÃO E TEMAS}

A distribuição das universidades participantes de um lado e outro do Atlântico (figura $\mathrm{n}^{\circ} 1$ ) é evidentemente relacionada à hierarquia urbana nos dois países, não é nenhuma surpresa constatar que Paris (na França) e Rio de Janeiro e São Paulo (no Brasil) destacam-se claramente do resto das cidades do país. Observa-se, contudo, a presença de cidades de dimensão mais limitada, por exemplo, Londrina, Maringá ou ainda Feira de Santana no Brasil, bem como o Le Mans ou Concarneau do lado francês.

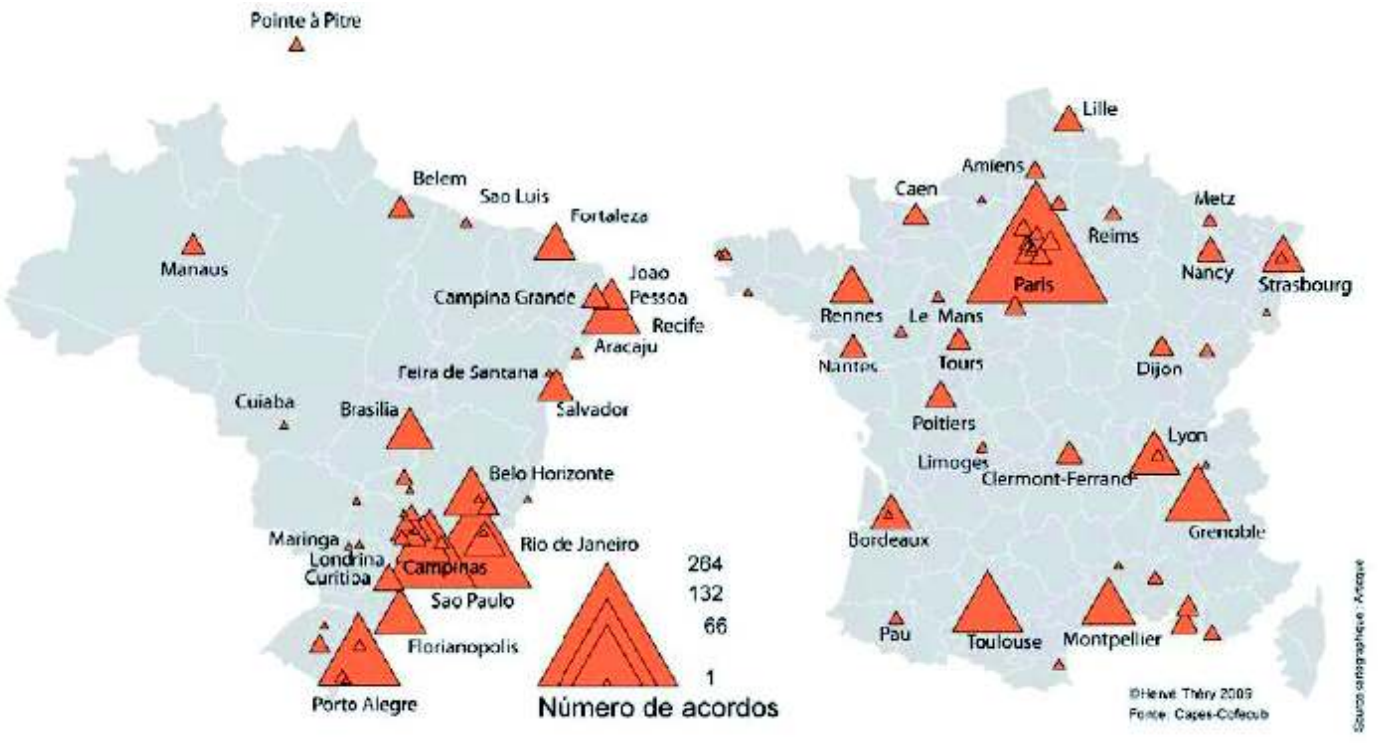

Figura 1 - As universidades participantes ao acordo Capes-Cofecub

A evolução dos acordos (figura $\mathrm{n}^{\circ} 2$ ) faz aparecer um aumento da parte das grandes capitais com a passagem das décadas: enquanto que Toulouse, por exemplo, destacava-se claramente nos anos 70 e 80 , o seu lugar reduz-se ao fio do tempo, enquanto que a de Paris aumenta, e simetricamente, a parte de Fortaleza ou Belém diminui. Pode-se explicar esta evolução pelo fato que, originalmente, o programa visava reforçar o potencial das universidades do Norte e o Nordeste, uma ambição de reequilíbrio geográfico que cedeu progressivamente o lugar à colaboração entre universidades de excelência, sem necessariamente tomar em conta esta dimensão territorial. 


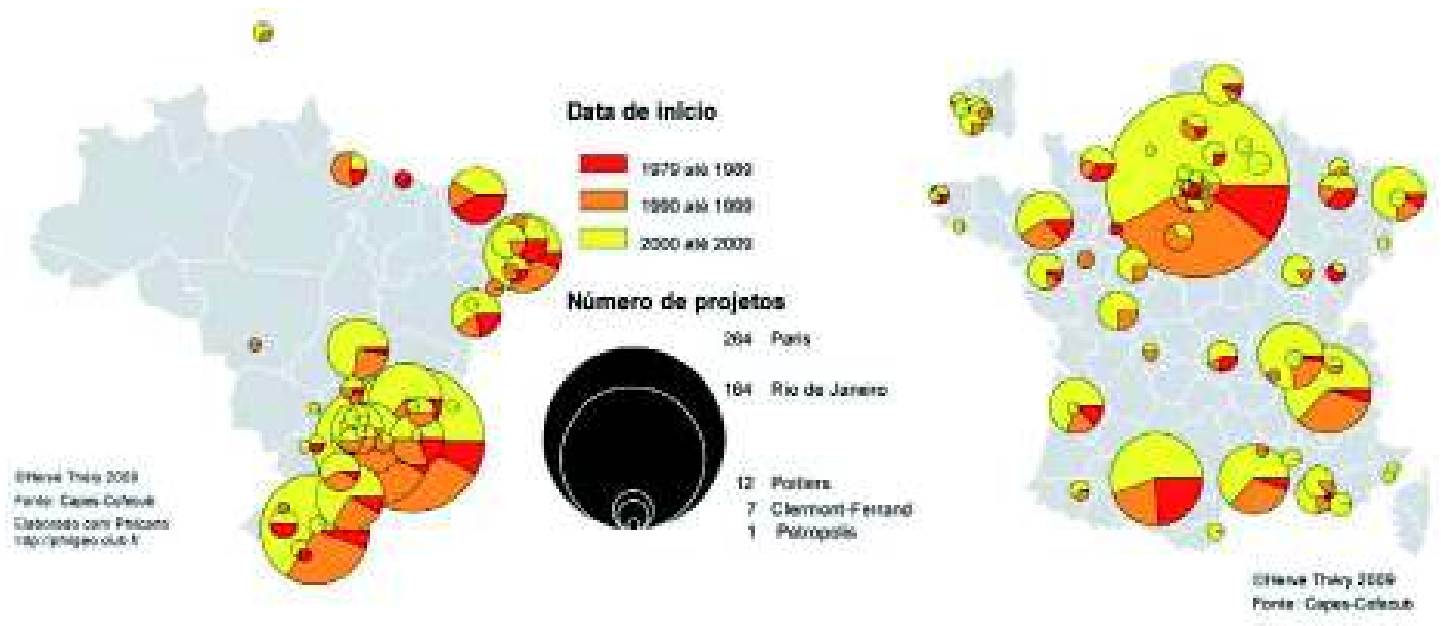

Figura 2 - Evolução por década

Em termos de distribuição por áreas científicas, o predomínio das ciências exatas e da Terra, seguidos pelas engenharias, é nítido, já que as duas juntas representam a metade dos projetos existentes durante estes 30 anos. As ciências humanas e a biologia as seguem de longe, as ciências agrárias e as ciências da saúde fecham a lista com percentagens inferiores à $10 \%$ do total.

Tabela 1 - Áreas científicas

\begin{tabular}{|c|c|}
\hline Área cientifica & projetos \\
\hline $\begin{array}{l}\text { Ciências exatas e da } \\
\text { terra }\end{array}$ & 242 \\
\hline Engenharias & 140 \\
\hline Ciências humanas & 103 \\
\hline Ciências biológicas & 101 \\
\hline $\begin{array}{l}\text { Ciências sociais } \\
\text { apticadas }\end{array}$ & 57 \\
\hline Ciências agrárias & 49 \\
\hline Ciências da saúde & 37 \\
\hline $\begin{array}{l}\text { Lingứistica, letras e } \\
\text { artes }\end{array}$ & 29 \\
\hline Multidisciplinar & 5 \\
\hline
\end{tabular}

Passando da distribuição global por áreas científicas à uma análise cidade por cidade, não se observa especialização muito marcada (fora raras exceções, como Brest ou Concarneau, Uberaba ou Vitória, que têm poucos projetos com seus homólogos do outro país) e é muito raro que cidades apareçam na figura 
$\mathrm{n}^{\circ} 3$ como círculos de uma única cor, o que indicaria que é ativa - no âmbito da cooperação francobrasileira - apenas em apenas uma área científica. Em todos os outros casos, as figuras em sector de círculo que representam as áreas científicas presentes em cada cidade mostram um bom equilíbrio, mesmo em cidades médias. No máximo pode-se notar a parte importante das engenharias em Nancy, das ciências exatas em Grenoble, das ciências agrárias em Viçosa e Piracicaba, dois centros universitários de nítida dominante agronômica.

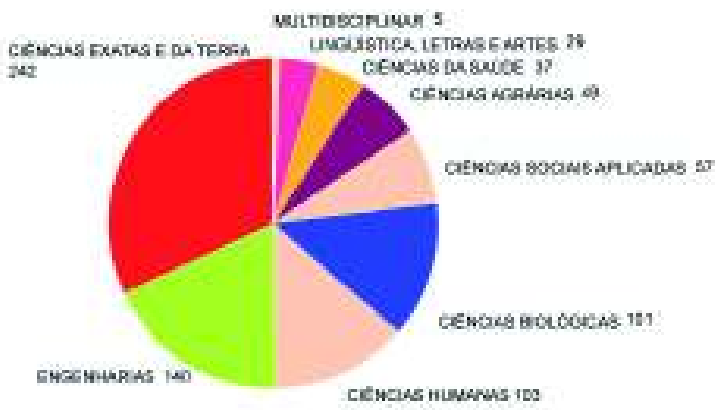

Figura 3 - Áreas científicas

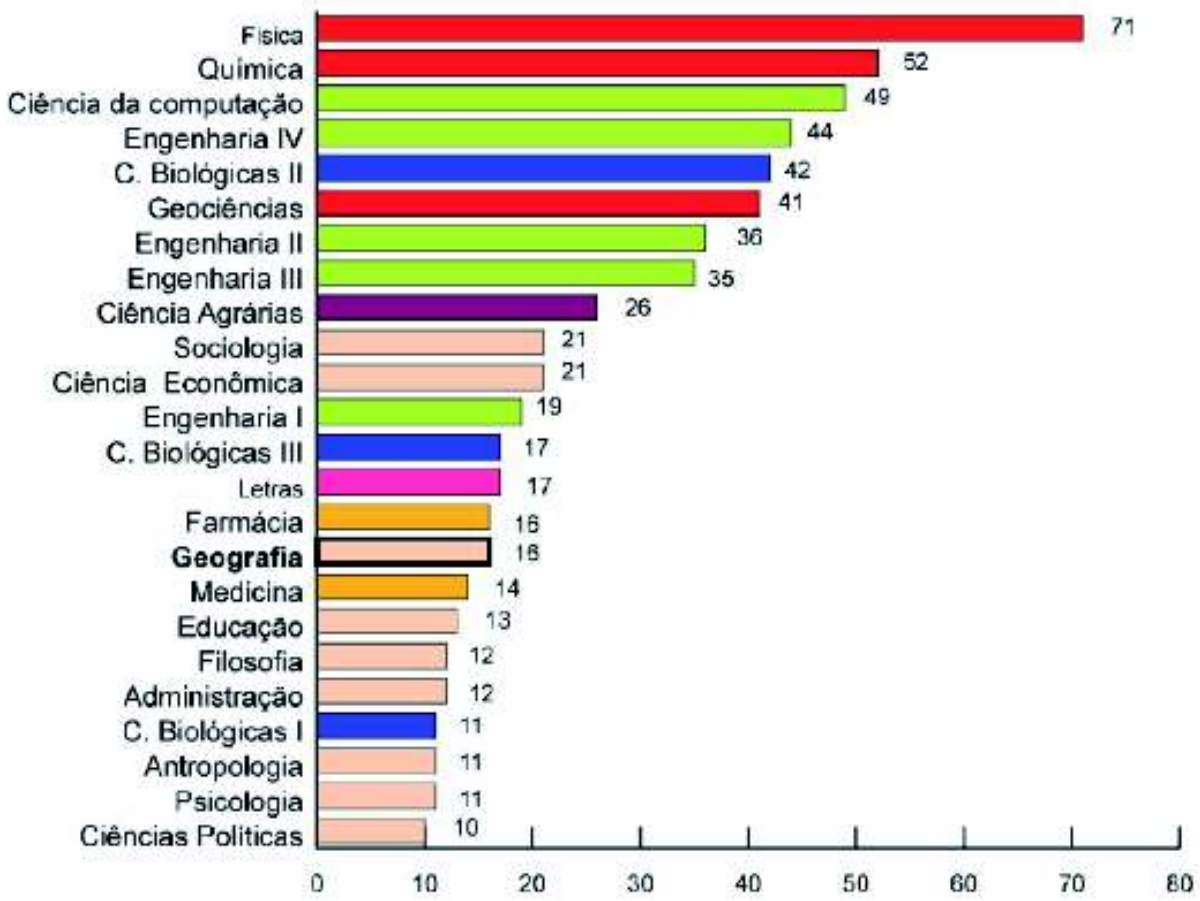


Tabela 2 - Área científica por cidade (dez primeiras cidade)

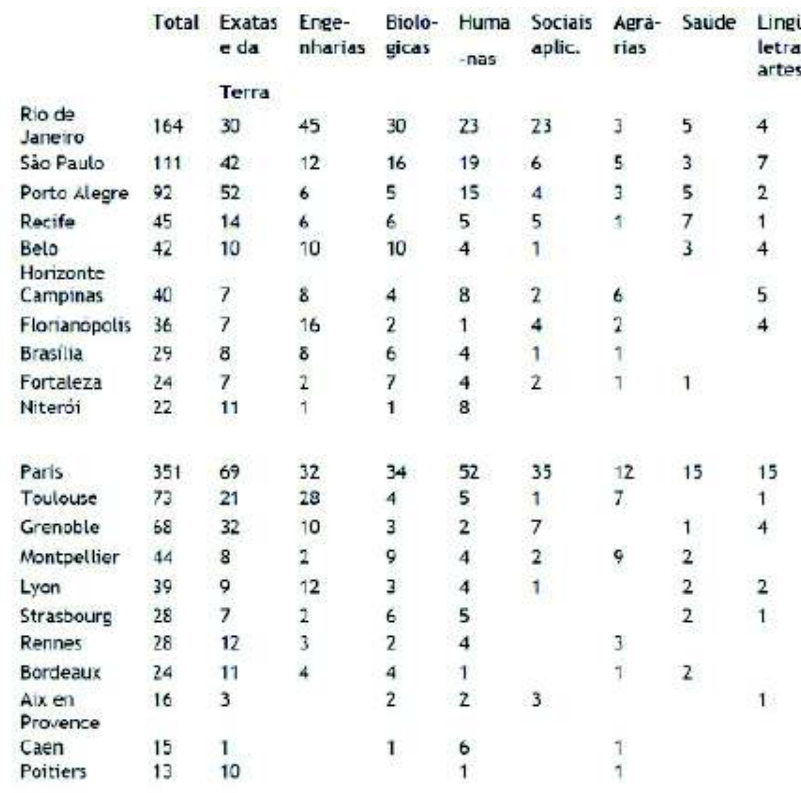

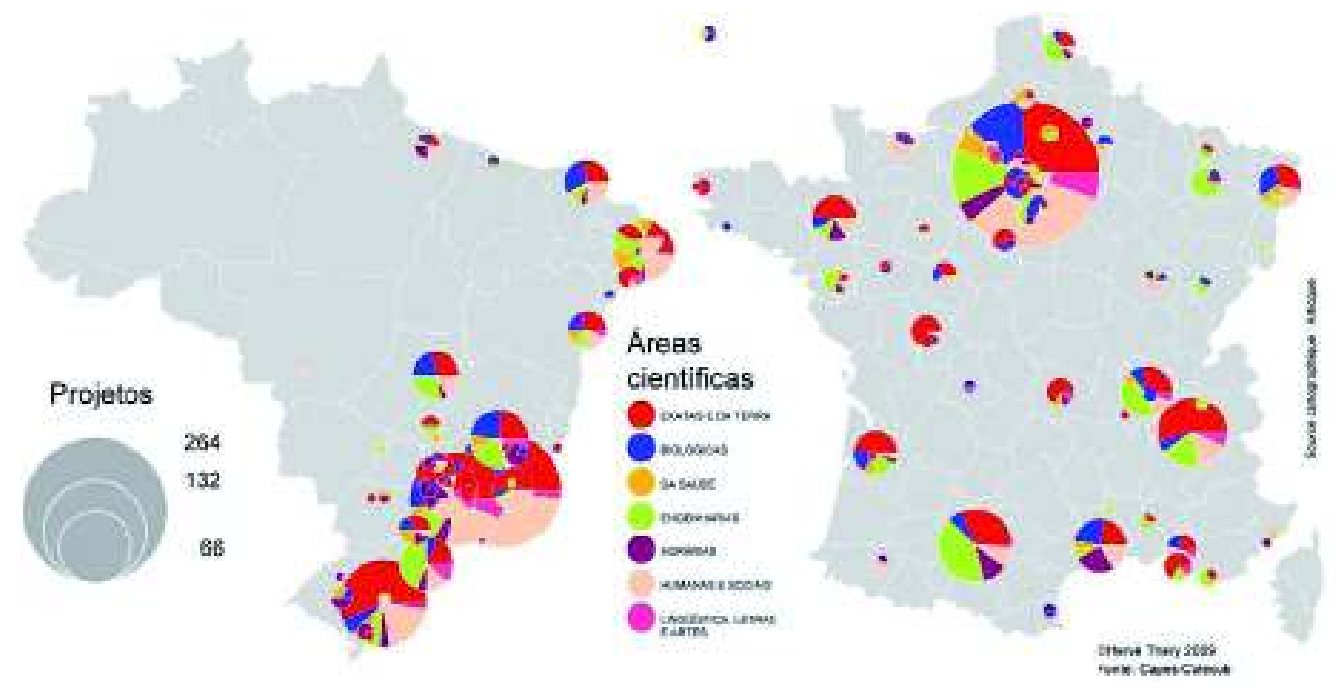

Figura 4 - Áreas científicas por cidade 


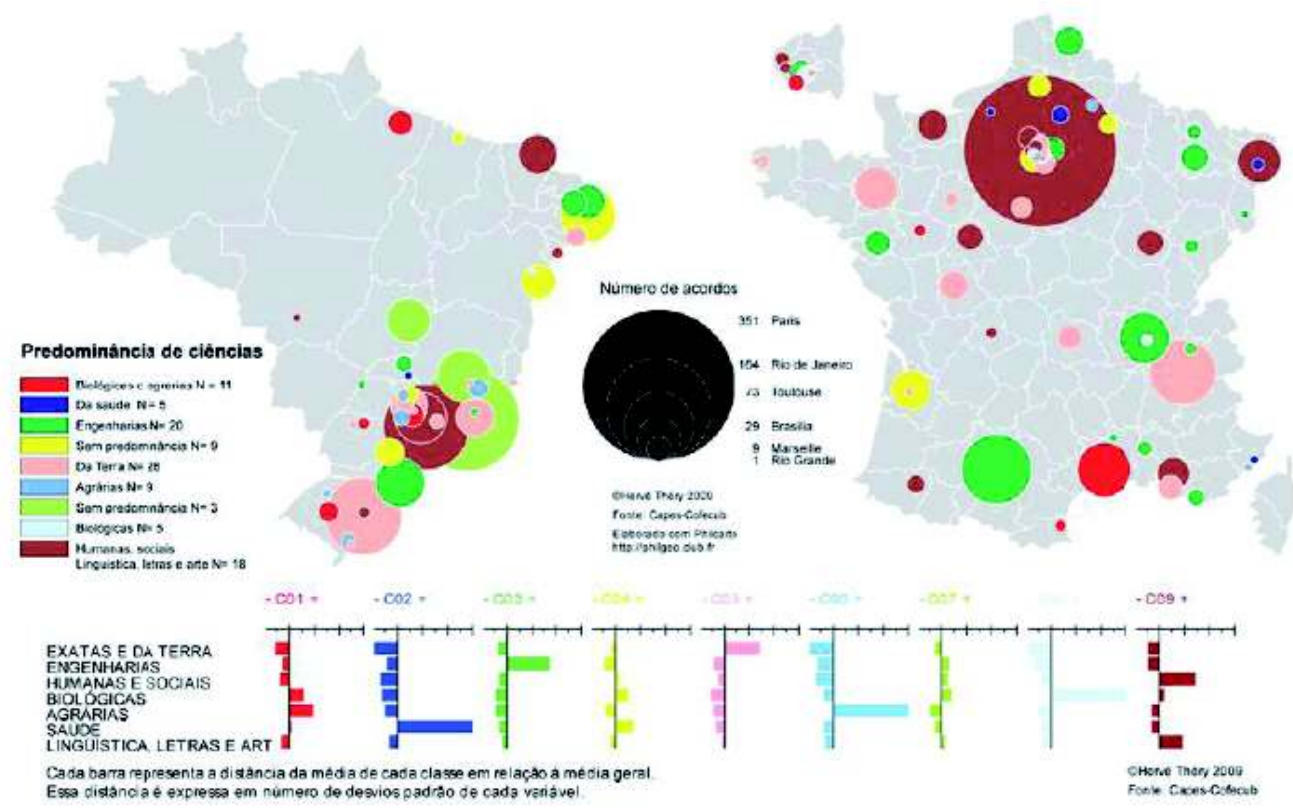

Figura 5 - Predominância de áreas ciêntificas por cidade

Uma análise de cluster (classificação hierárquica ascendente, figura $n^{\circ} 5$ ) permite sintetizar estas "especializações" das cidades universitárias ao determinar perfis por área científica onde as cidades se situam, por terem um numero de projetos acima da média (barras à direitas) ou abaixo dela (barras à esquerda) para tal ou tal área: por exemplo, em ciências agrários destacam-se Botucatu e Viçosa, em ciências da Terra Porto Alegre, Grenoble e Rennes, em ciências humanos e sociais, lingüística, letras e artes Paris e São Paulo, etc.

\section{OS FLUXOS PRINCIPAIS}

Representar as colaborações que existem entre universidades francesas e brasileiras, no âmbito do programa Capes-Cofecub, sob a forma de mapas de fluxos desenha um emaranhado denso (figura $\mathrm{n}^{\circ} 5$ ), tão denso que é necessário, para mais clareza, reduzi-lo aos casos mais numerosos (figura $\mathrm{n}^{\circ} 6$ ), e vale a pena analisar de perto diversas delas, que revelam afinidades entre os estabelecimentos, ou pelo menos entra as equipes que trabalham nelas.

As principais colaborações, vistas do lado brasileiro, referem-se às cidades de Rio de Janeiro de Janeiro, São Paulo, Porto Alegre, Belo Horizonte e Brasília, as outras cidades tendo menos projetos com os seus homólogos franceses, ao ponto que puderam ser agrupadas na figura $\mathrm{n}^{\circ} 9$. 


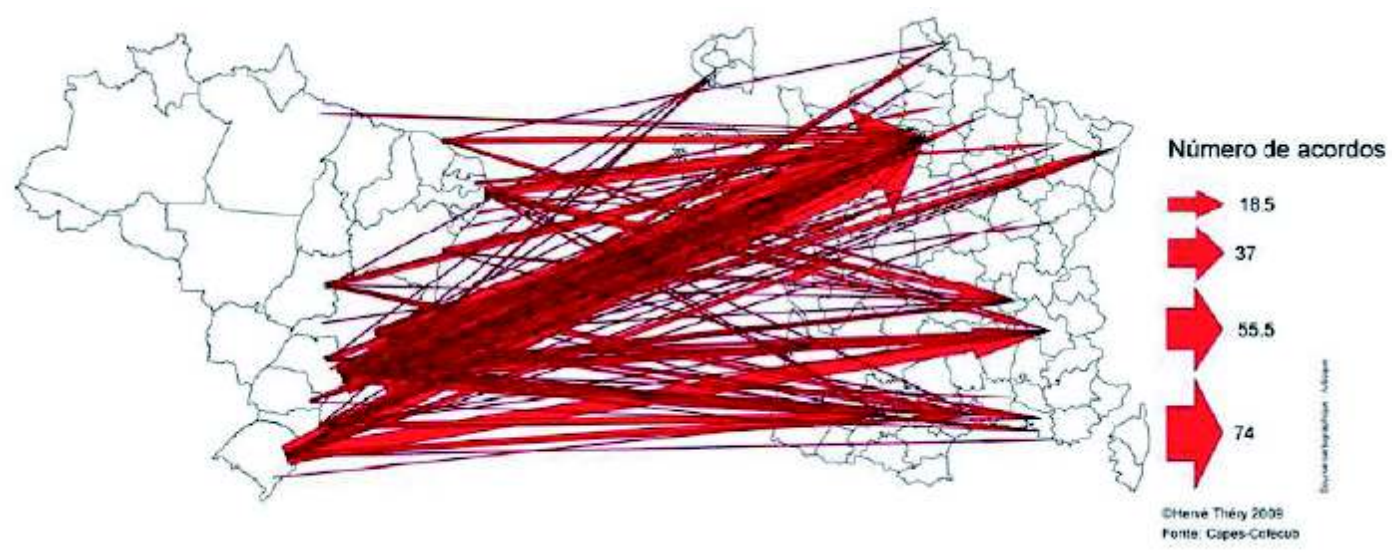

Figura 6 - Número global de projetos
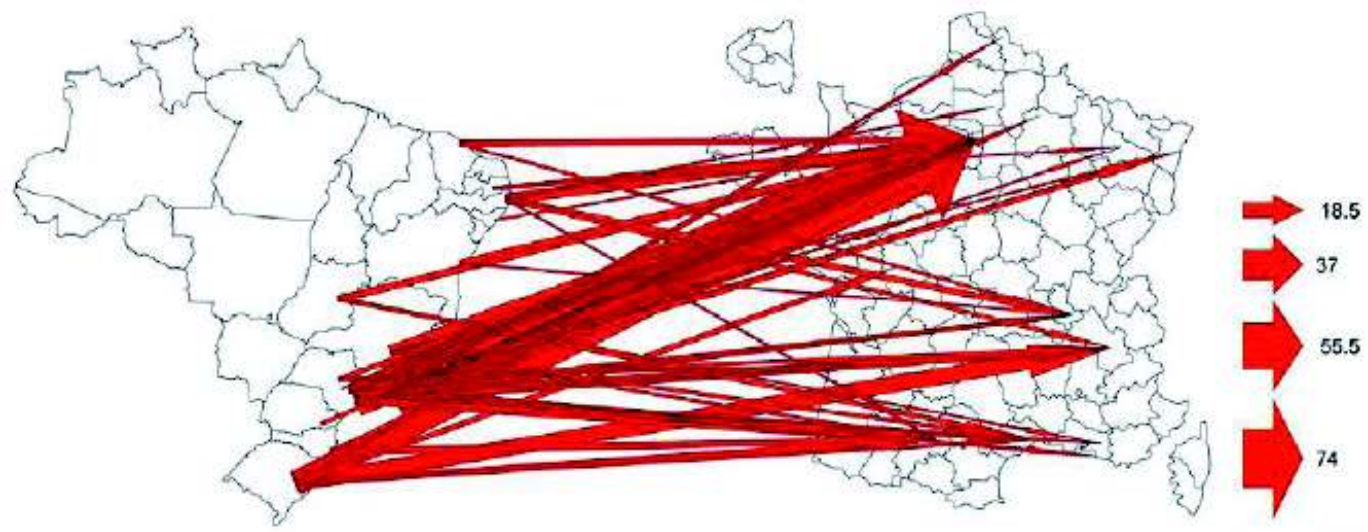

CHerve thery zons Fanle: Capes Colecub

Figura 7 - Mais de três projetos

Os projetos oriundos do Rio de Janeiro têm principalmente parceiros em Paris, como o mostra a sets espessa da figura $n^{\circ} 7$, o que não é tão claramente o caso para São Paulo. Esta cidade desenvolve colaborações importantes com Grenoble Montpellier e Toulouse, o que equilibra um pouco melhor os fluxos com a França. No caso de Porto Alegre, o peso de Grenoble e de Toulouse é suficientemente forte para quase igualar o de Paris, enquanto que Belo Horizonte reproduz, em uma escala menor, o estilo de Rio de Janeiro. Nas outras cidades o número de projetos não é suficiente para que se possa tirar conclusões claras, mas em todo é Paris, e secundariamente Grenoble, que se destacam. 
Tabela 3 - Principais intercâmbios por cidades (mais de nove

$\begin{array}{cll}\text { Acordos } & \begin{array}{l}\text { Cidade } \\ \text { brasileira }\end{array} & \text { Cidade francesa } \\ 74 & \text { Rio de Janeiro } & \text { Paris } \\ 42 & \text { São Paulo } & \text { Paris } \\ 29 & \text { Porto Alegre } & \text { Paris } \\ 20 & \text { Porto Alegre } & \text { Grenoble } \\ 14 & \text { Recife } & \text { Paris } \\ 13 & \text { Belo Horizonte } & \text { Paris } \\ 11 & \text { Rio de Janeiro } & \text { Toulouse } \\ 11 & \text { São Paulo } & \text { Toulouse } \\ 10 & \text { São Paulo } & \text { Grenoble } \\ 9 & \text { Niterói } & \text { Paris } \\ 9 & \text { Campinas } & \text { Paris } \\ 9 & \text { Florianopolis } & \text { Toulouse } \\ 9 & \text { Brasilia } & \text { Paris }\end{array}$

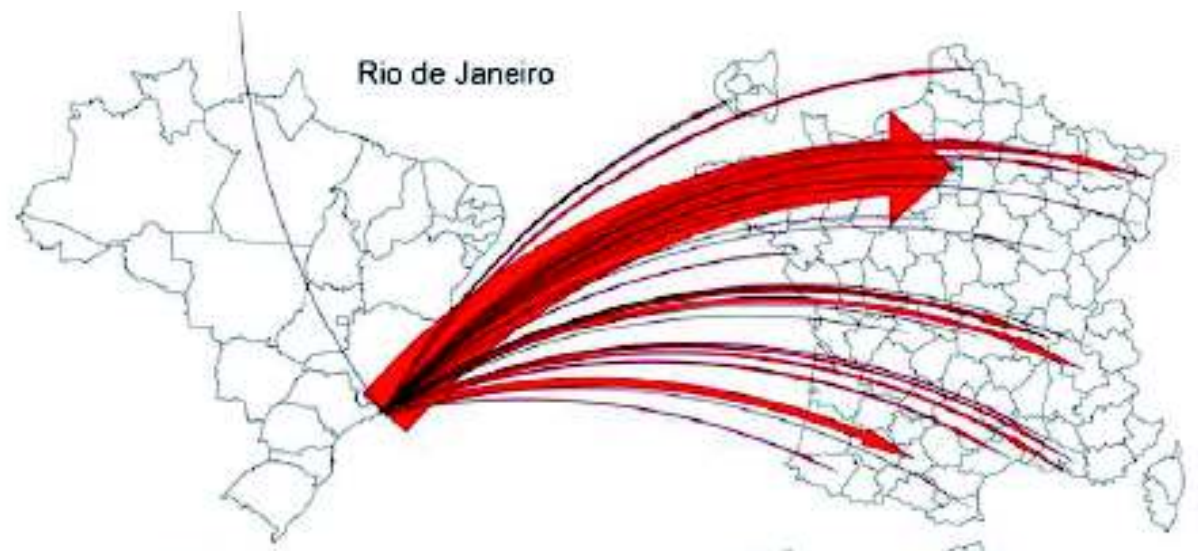

Nombre d'accords

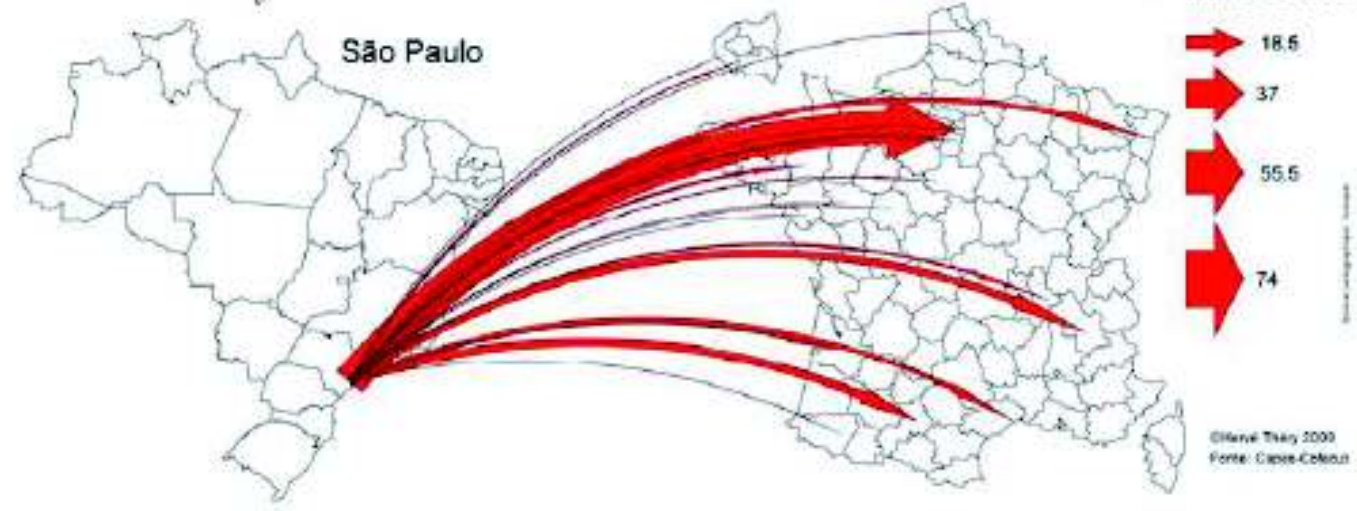


Figura 8 - Rio de Janeiro e São Paulo

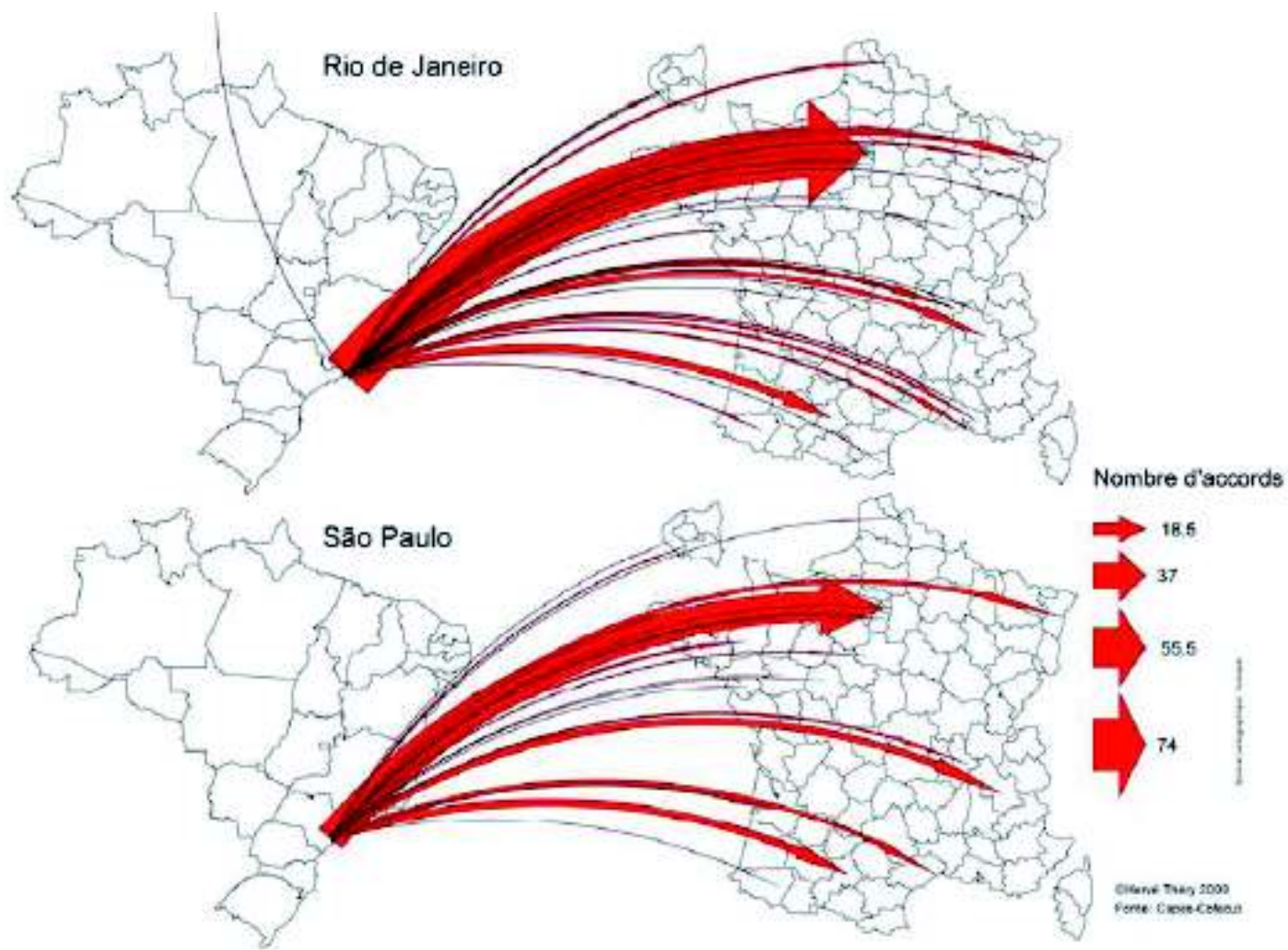

Figura 9 - Porto Alegre e Belo Horizonte

Os projetos vistos do lado francês enfatizam a dominância de Paris, já que é nesta cidade que se situam os parceiros escolhidos com mais freqüência pelas universidades brasileiras: os fluxos que procedem dela são numerosos e potentes, e dirigem-se principalmente para o Sul e o sudeste do país, as regiões mais desenvolvidas no plano econômico, mas também no plano científico. A partir de Toulouse, de Grenoble, de Montpellier e de Rennes os fluxos de projetos ligam-se igualmente às mesmas regiões do país, de maneira mais concentrada ainda, a única exceção ao norte de Minas Gerais sendo Brasília. As outras grandes cidades universitárias fazem escolhas similares, privilegiando o Sul e Sudeste em detrimento do Nordeste, com o qual os projetos são pouco numerosos, e mais ainda o Norte amazônico, que não conta praticamente nenhum deles. 


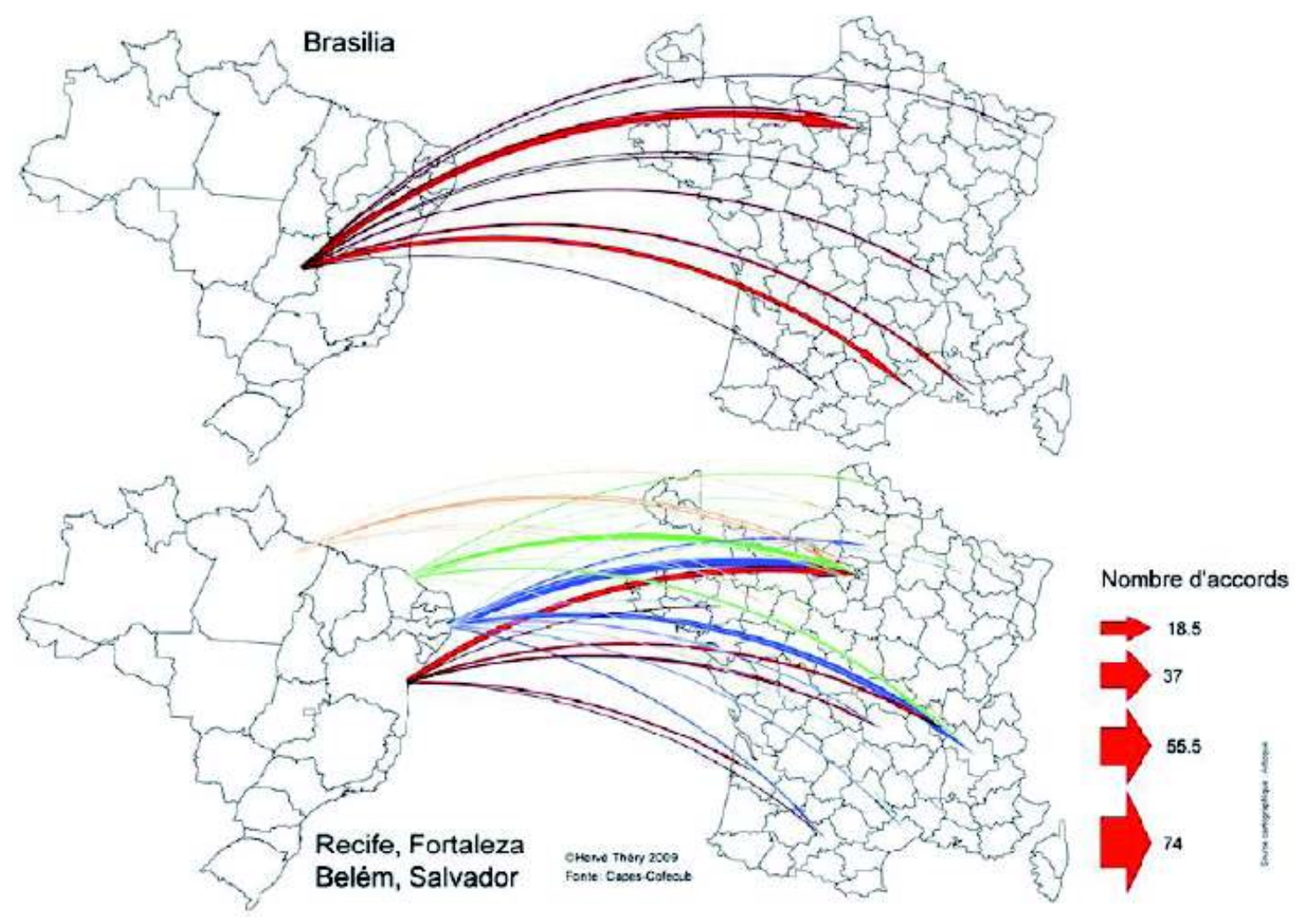

Figura 10 - Brasília e outras cidades

\section{O CASO DA GEOGRAFIA}

No caso específico da geografia, que nós interessa mais diretamente, os centros principais são igualmente Paris e a região parisiense do lado francês, e o triângulo das capitais do Sudeste (Rio de Janeiro de Janeiro, São Paulo e Belo Horizonte) do lado brasileiro. Três capitais situadas nas regiões mais periféricas do Sul, o Nordeste e Centro-Oeste, Recife, Porto Alegre e Cuiabá, conseguiram montar os seus próprios projetos. No caso de Recife, foi com Paris, mas para Cuiabá a parceira foi Rennes e para Porto Alegre foi a universidade do Mans, uma nova vinda no mapa das colaborações franco-brasileiras. Do lado francês a distribuição é menos centrada na região capital, tem-se espaço para Estrasburgo, Pau e Montpellier, bem como para Rennes e Le Mans, já citados. Nota-se aqui a ausência de cidades dotadas de importantes departamentos de geografia, como Toulouse ou Grenoble, o que indica incontestavelmente que as relações com o Brasil não são automáticas, mas supõem iniciativas de equipes e de pessoas capazes de estabelecer pontes com os seus homólogos brasileiros. 

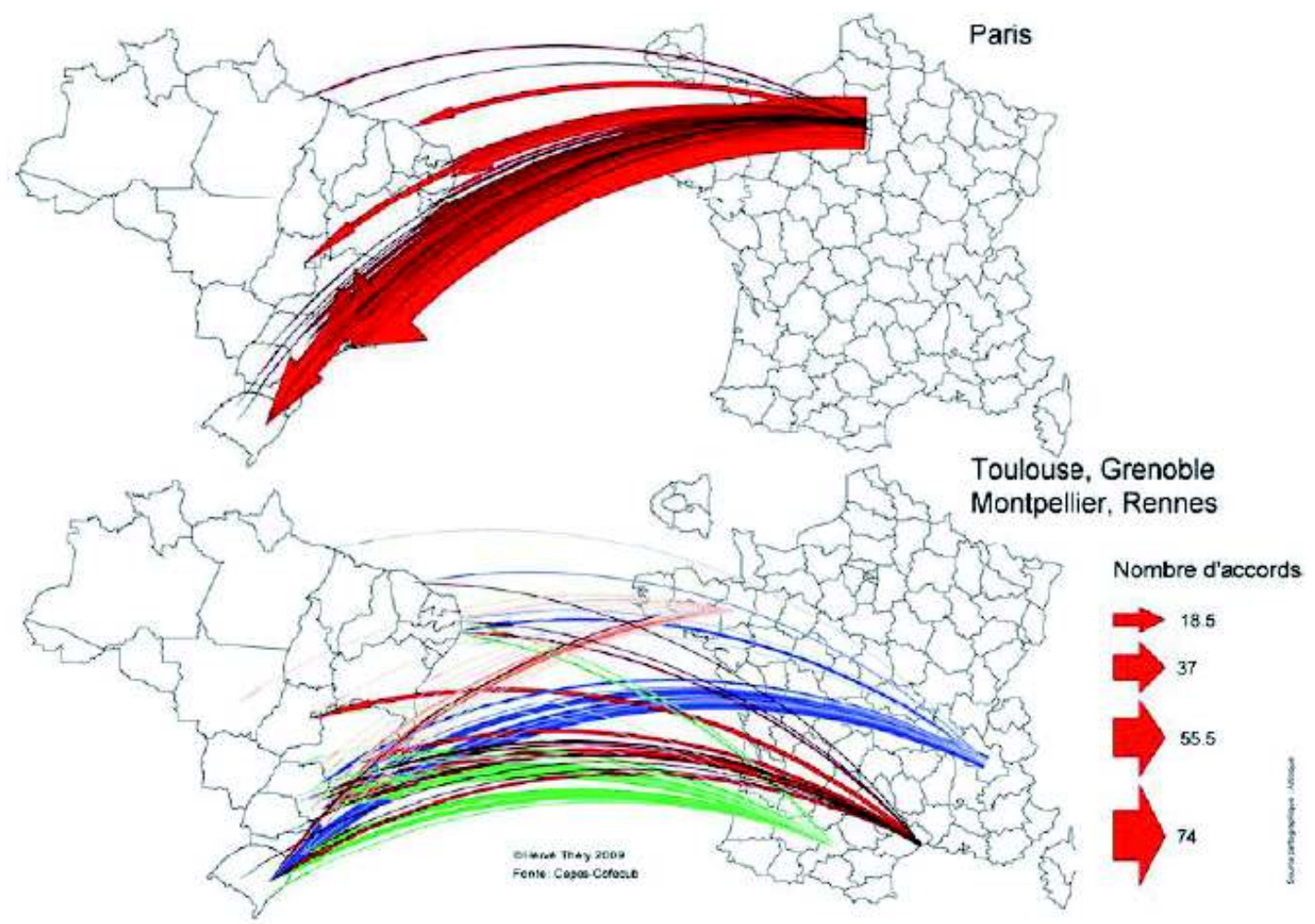

Figura 11 - Paris, Toulouse, Grenoble, Montpellier e Rennes

É o que confirma o exame da lista dos projetos aprovados, em geografia, ao longo destes 30 anos. Nela vêem-se personalidades bem conhecidas no pequeno mundo dos "brasilianistas" franceses, e os seus homólogos brasileiros, não menos notórias nas suas respectivos áreas. $\mathrm{O}$ fato de um projeto seja encabeçado por J.Pereira de Queiróz e A. Ruellan, por exemplo, deve ter pesado mais, na avaliação, que os méritos respectivos da USP e da Universidade Rennes, por maiores que sejam. Podemos encontrar a confirmação disso ao notar que o mesmo A. Ruellan obteve um novo projeto em Montpellier, J.Pereira de Queiróz continuando então o antigo projeto, nesta vez com a Universidade Paris VII. Da mesma maneira, tanto P.C. da Costa Gomes e V. Berdoulay como G. Cocco e A. Bourdin puderam renovar seu acordo, sobre um tema vizinho do primeiro.

É inegável que o fundamento de um bom projeto Capes-Cofecub, capaz de durar e de se renovar, é o bom relacionamento entre pessoas que se conhecem e confiam umas nas outras, que sabem poder contar uma com a outra no momento de montar equipes e programa de pesquisa. Neste caso, como em muitos outros, a configuração que o mapa permite detectar e mostrar é a resultante de uma decisão de pequenos grupos - neste caso das equipes candidatas - e até mesmo a ação individual de pessoas. Mas não é isso uma ocorrência bastante comum em geografia, a singularidade que dá fundamento ao seu lugar nas ciências sociais, a curiosidade para as configurações territoriais que derivam das escolhas feitas pelas sociedades? 


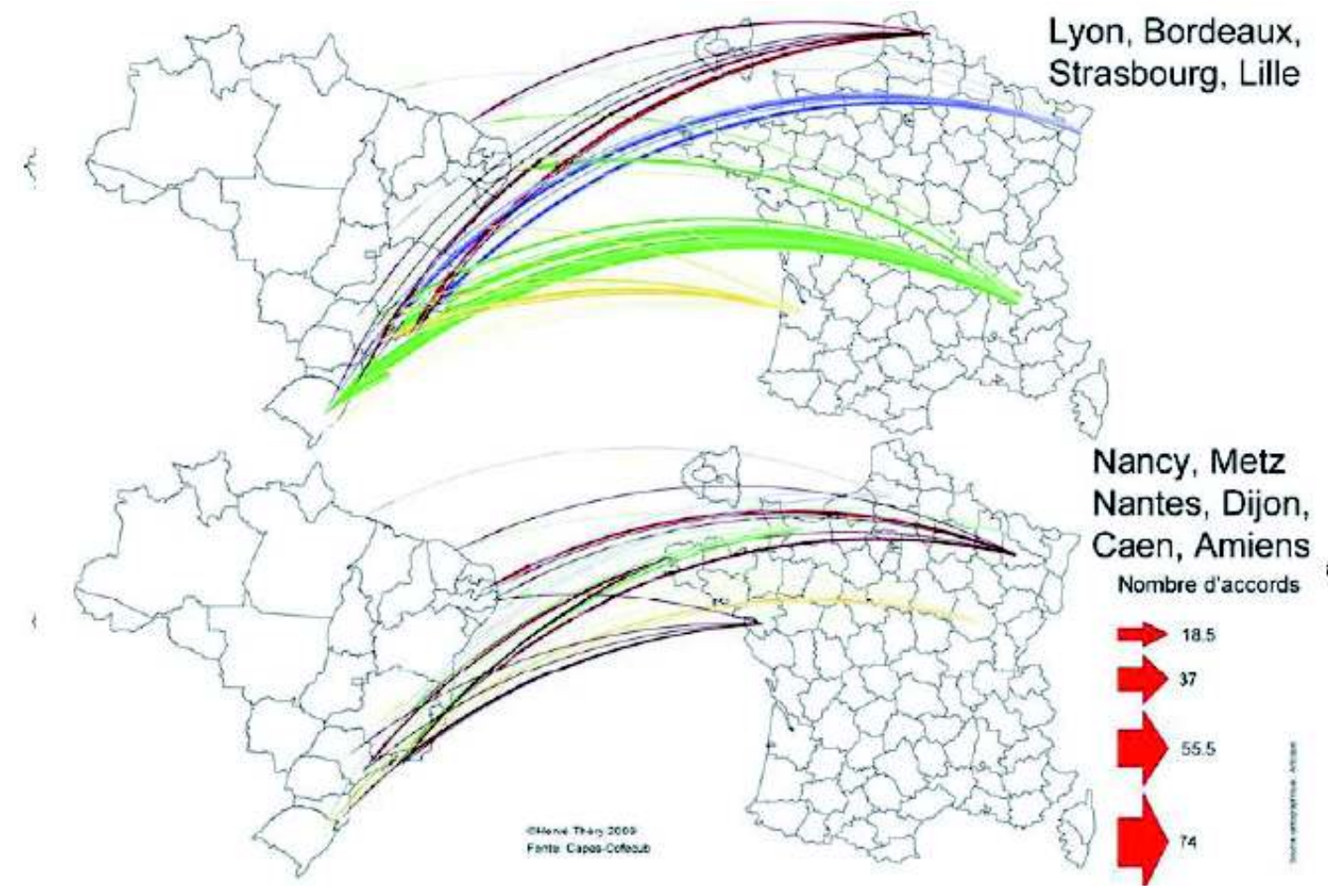

Figura 12 - Outras grandes cidades

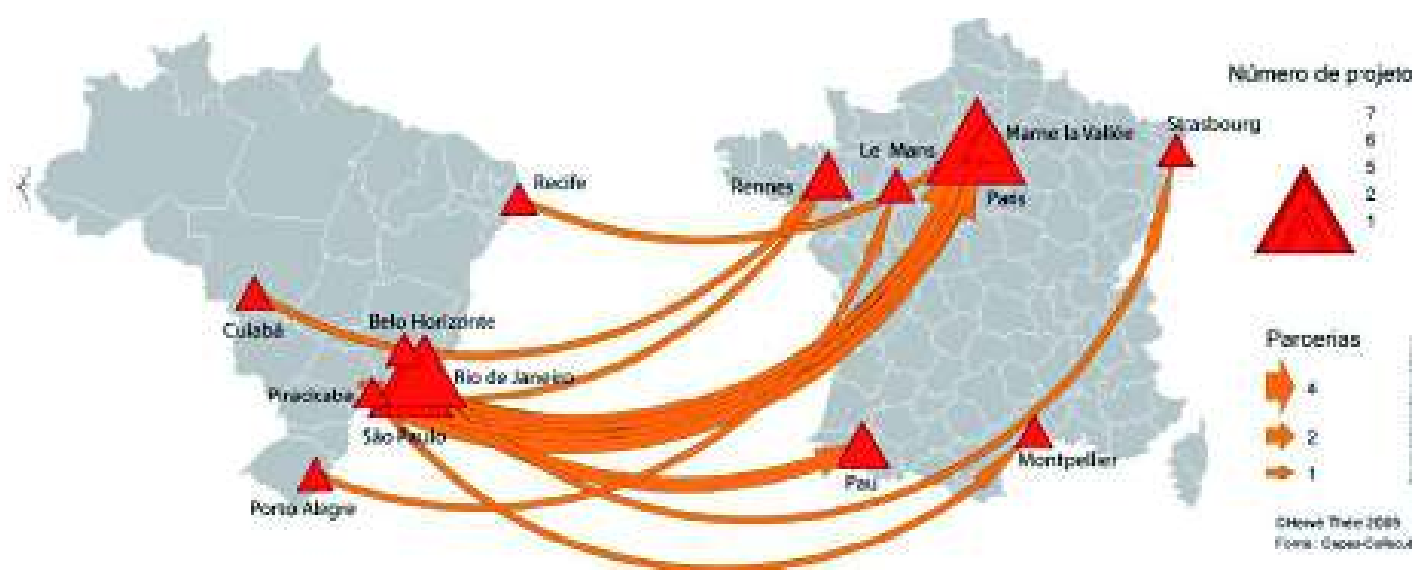

Figura 13 - 
Tabela 4 - Acordos em geografia, os parceiros

\begin{tabular}{|c|c|c|c|c|c|c|}
\hline Projeto & $\begin{array}{l}\text { Coordenador } \\
\text { brasileiro }\end{array}$ & $\begin{array}{l}\text { Instituição } \\
\text { brasileira }\end{array}$ & $\begin{array}{l}\text { Cidade } \\
\text { brasileira }\end{array}$ & $\begin{array}{l}\text { Coordenador } \\
\text { francês }\end{array}$ & $\begin{array}{l}\text { Instituiçăo } \\
\text { francesa }\end{array}$ & $\begin{array}{l}\text { Cidade } \\
\text { Francesa }\end{array}$ \\
\hline $035 / 87$ & $\begin{array}{l}\text { J.Pereira de } \\
\text { Queiráz }\end{array}$ & USP & São Paulo & A. Ruellan & U. Rennes & Rennes \\
\hline $125 / 91$ & A. Saadi & UFMG & $\begin{array}{l}\text { Belo } \\
\text { Horizonte }\end{array}$ & H. Vogt & ULP & Strasbourg \\
\hline $083 / 87 / 92$ & N.Lacerda & UFPE & Recife & C. Gros & U. Paris III & Paris \\
\hline $151 / 94$ & $\begin{array}{l}\text { S. Simòes de } \\
\text { Castro }\end{array}$ & USP & São Paulo & A. Ruellan & CNEARC & Montpellier \\
\hline $005 N / 96$ & $\begin{array}{l}\text { G. Tomasini } \\
\text { Maitelli }\end{array}$ & UFMT & Cuiabá & R. Bariou & Rennes II & Rennes \\
\hline $190 / 96$ & $\begin{array}{l}\text { C.Egler / I. de } \\
\text { Castro }\end{array}$ & UFRJ & $\begin{array}{l}\text { Rio de } \\
\text { Janeiro }\end{array}$ & M. Droulers & U. Paris III & Paris \\
\hline $333 / 00 / 02$ & $\begin{array}{l}\text { P.C. da Costa } \\
\text { Gomes }\end{array}$ & UFRJ & $\begin{array}{l}\text { Rio de } \\
\text { Janeiro }\end{array}$ & V.Berdoulay & U. de Pau & Pau \\
\hline $409 / 02 / 04$ & $\begin{array}{l}\text { A. I. Geraiges } \\
\text { Lemos }\end{array}$ & USP & São Paulo & $H$. Therry & ENS & Paris \\
\hline $412 / 03 / 05$ & $\begin{array}{l}\text { J.Pereira de } \\
\text { Queiróz }\end{array}$ & USP & Sāo Paulo & M. Fort & U. Paris 7 & Paris \\
\hline $429 / 03 / 05$ & G. Cocco & UFRJ & $\begin{array}{l}\text { Rio de } \\
\text { Janeiro }\end{array}$ & A. Bourdin & UMV & $\begin{array}{l}\text { Marne la } \\
\text { Vallée }\end{array}$ \\
\hline $483 / 05$ & $\begin{array}{l}\text { Célia Regina } \\
\text { Montes }\end{array}$ & USP/Esalq & Piracicaba & G. Calas & U. Paris VI & Paris \\
\hline $2006 \cdot 18$ & G. Cocco & UFRJ & $\begin{array}{l}\text { Rio de } \\
\text { Janeiro }\end{array}$ & A. Bourdin & UMV & $\begin{array}{l}\text { Marne la } \\
\text { Vallée }\end{array}$ \\
\hline $2007 \cdot 114$ & $\begin{array}{l}\text { P.C. da Costa } \\
\text { Gomes }\end{array}$ & UFRJ & $\begin{array}{l}\text { Rio de } \\
\text { Janeiro }\end{array}$ & V.Berdoulay & U Pau & Pau \\
\hline $2007 \cdot 116$ & R. Verdum & UFRGS & $\begin{array}{l}\text { Porto } \\
\text { Alegre }\end{array}$ & J.Cobornnois & $\begin{array}{l}\text { U du } \\
\text { Maine }\end{array}$ & Le Mans \\
\hline $2008-71$ & $\begin{array}{l}\text { A.F.Alessandri } \\
\text { Carlos }\end{array}$ & USP & São Paulo & $H$. Thery & U. Paris III & Paris \\
\hline
\end{tabular}

Tabela 5 - Acordos em geografia, os temas

\begin{tabular}{|c|c|}
\hline Nùmero & Titulo do projeto \\
\hline $035 / 37$ & Pedologia. \\
\hline $125 / 91$ & Geomortologia: as margens sul. e leste do craton do São Francisco. \\
\hline $083 / 87 / 92$ & Poder territoria e tecnologia. \\
\hline $151 / 94$ & $\begin{array}{l}\text { Morfalogia dos sistemas pedologicos tropicaisi relacker entre funcionamentos } \\
\text { e fertilidades. }\end{array}$ \\
\hline $005 N / 96$ & Ecossistema e orginizaçio de expaço na Amazônia. \\
\hline $190 / 96$ & Geogratia, gestio do territória e desenvalvimento sustentivel. \\
\hline $333 / 00 / 02$ & Os lugares da politica: expaços publices e espacos de gestào \\
\hline $409 / 02 / 04$ & $\begin{array}{l}\text { Desafios da mundlatizacto e as dinàmicas reguonais no Brasil e na anerica de } \\
\text { Sul. }\end{array}$ \\
\hline $412 / 03 / 05$ & Processes fisicos -hidricos e biegecquimicas no Pantanal da Nhecolandia e suas \\
\hline $429 / 03 / 05$ & $\begin{array}{l}\text { representaçes espacias A cidade, territiono produtwo; rodes, cooperapoes e } \\
\text { governancari }\end{array}$ \\
\hline $483 / 05$ & Podzolizaça das Lateritas da alta bactia amazónica \\
\hline $2006-18$ & A cidade, territorio produtive: redes, cooperaçoes e governanças \\
\hline $2006-3$ & Processos fisicos - hidricos e biegeoquimicos no Pantanal da Nenecolandia e suass \\
\hline $2007-114$ & $\begin{array}{l}\text { representacoses espacias Os cenarios da urbanidade: imarens, espacos e } \\
\text { identidade. }\end{array}$ \\
\hline $2007-116$ & $\begin{array}{l}\text { Avenizaçăo e gestáo dos recursos hidricos na bacia hadrografica do Rio ibicui- } \\
\text { Rio Grande do Sul - Brasil. }\end{array}$ \\
\hline 2009.7 & $\begin{array}{l}\text { Diferenciacbo e dindmica espaciali escalas, processos e instrumentos de } \\
\text { observac,ao. }\end{array}$ \\
\hline
\end{tabular}

\section{REFERÊNCIAS BIBLIOGRÁFICAS}

Capes http://www.capes.gov.br/cooperacao-internacional/franca/cofecub, 5/8/2009

Cofecub http://www.egide.asso.fr/jahia/Jahia/lang/fr/accueil/appels/cofecub, 19/5/09 
Adit http://www.bulletins-electroniques.com/actualites/59359.htm, 7/8/2009

Charge http://www.jornaldaciencia.org.br/include/popCharge.html, 7/8/2009

Ano da França http://anodafrancanobrasil.cultura.gov.br/fr/2009/05/25/seminario-comemora-30-anos-decooperacaofranco-brasileira-com-resultados-positivos/, 7/8/2009.

Recebido em abril de 2009

Aceito em agosto de 2009 